\title{
The influence of primary health care organizational models on patients' experience of care in different chronic disease situations
}

\author{
R. Pineault, MD, PhD (1,2,3); S. Provost, MD, MSc (1,2); M. Hamel, MSc (1,2); A. Couture, MSc (1,2); J.F. Levesque, MD, PhD (1,2,3)
}

\begin{abstract}
Objectives: To examine the extent to which experience of care varies across chronic diseases, and to analyze the relationship of primary health care (PHC) organizational models with the experience of care reported by patients in different chronic disease situations.
\end{abstract}

Methods: We linked a population survey and a PHC organizational survey conducted in two regions of Quebec. We identified five groups of chronic diseases and contrasted these with a no-chronic-disease group.

Results: Accessibility of care is low for all chronic conditions and shows little variation across diseases. The contact and the coordination-integrated models are the most accessible, whereas the single-provider model is the least. Process and outcome indices of care experience are much higher than accessibility for all conditions and vary across diseases, with the highest being for cardiovascular-risk-factors and the lowest for respiratory diseases (for people aged 44 and under). However, as we move from risk factors to more severe chronic conditions, the coordination-integrated and community models are more likely to generate better process of care, highlighting the greater potential of these two models to meet the needs of more severely chronically ill individuals within the Canadian health care system.

Keywords: chronic disease, organizational models, primary health care, continuity of care, accessibility of care, process of care, outcome of care, Quebec

\section{Introduction}

As our population ages, management of chronic diseases has become a prime concern for policy makers and clinicians alike. ${ }^{1,2}$ Health care systems need to shift from a disease-focused approach to one that is more holistic and comprehensive. ${ }^{2-5}$ One convincing argument for adopting case- rather than disease-management approaches is the high prevalence of comorbidities associated with the presence of a chronic disease. ${ }^{1,5,6}$ Indeed, only $10 \%$ of chronically ill individuals present a single morbidity, whereas $60 \%$ present at least four. ${ }^{7}$ For these reasons, the optimal setting for achieving case management for the chronically ill could arguably be in primary care. ${ }^{4,8}$

Several proposals have focused on approaches linked with primary health care (PHC) that advocate more accessible and coordinated patient-centred care, thus emphasizing health promotion and disease prevention. ${ }^{9-11}$ Modalities of care such as those proposed in the chronic care model and its derivatives have shown great potential for achieving such results. ${ }^{12-14}$
However, less attention has been paid to the organizational contexts in which these modalities of care are implemented. ${ }^{15}$ These integrated models of chronic care do not specify in which type of organization and under what organizational modalities such improvements in chronic care are most likely to occur. However, some studies have explored the association between structural features of PHC practices and their performance, including experience of care. ${ }^{14,16,17}$ A recent study in Ontario found that chronic disease management was superior in community health centres compared with other types of practices. ${ }^{18}$ Another Ontario study compared two models of primary care delivery where the main difference was the way physicians were paid, with one being enhanced fee-for-service and the other capitation. ${ }^{19}$ However, few studies have examined PHC practices as complex organizational entities. . $^{14,17,20,21}$ Further, to our knowledge no study has looked at variations in experience of care across different chronic conditions in relation to various PHC organizational models.

The objectives of this article are to examine the extent to which experience of care varies across chronic diseases and to analyze the relationship of PHC organizational models with the experience of care reported by patients in different chronic disease situations.

\section{Methods}

\section{Research design}

Our study consisted of two interrelated surveys. The first, a population-based telephone survey, involved 9206 randomly

Author references

1. Direction de santé publique de l'Agence de la santé et des services sociaux de Montréal, Montréal, Quebec, Canada

2. Institut national de santé publique du Québec, Québec, Quebec, Canada

3. Centre de recherche du Centre hospitalier de l'Université de Montréal, Montréal, Quebec, Canada

Correspondence: Raynald Pineault, Direction de santé publique, Agence de la santé et des services sociaux, 1301 rue Sherbrooke Est, Montréal QC H2L 1M3;

Tel.: (514) 528-2400 ext. 3480; Fax: (514) 528-2470; Email: rpineaul@santepub-mtl.qc.ca 
TABLE 1

Results of factor analysis for $\mathbf{2 3}$ variables of care experience according to survey respondents $(\mathrm{N}=6222)$ having a regular source of primary care, Quebec, 2003-2005

\begin{tabular}{|c|c|c|}
\hline Experience of care & $\begin{array}{l}\text { Number } \\
\text { of variables }\end{array}$ & $\begin{array}{l}\text { Cronbach reliability } \\
\text { coefficient }\end{array}$ \\
\hline First-contact accessibility & 4 & 0.579 \\
\hline \multicolumn{3}{|l|}{ If the doctor who is responsible for your care is not available, you can see another doctor at your regular clinic } \\
\hline \multicolumn{3}{|l|}{ If you need to see a doctor for a new health problem, you go to your regular clinic first } \\
\hline \multicolumn{3}{|l|}{$\begin{array}{l}\text { If you need to see a doctor on the same day for a health problem such as fever or a slight accident, you } \\
\text { go to your regular clinic first }\end{array}$} \\
\hline \multicolumn{3}{|l|}{ When you consult a doctor at your regular clinic, you go directly there without making an appointment } \\
\hline Process of care & 14 & 0.848 \\
\hline \multicolumn{3}{|l|}{ Affiliation continuity } \\
\hline \multicolumn{3}{|l|}{ You see the same doctor when you go to your regular clinic } \\
\hline \multicolumn{3}{|l|}{ At your regular clinic, your medical history is known } \\
\hline \multicolumn{3}{|l|}{ At your regular clinic, the doctors/staff are aware of all the prescription medications you take } \\
\hline \multicolumn{3}{|l|}{$\begin{array}{l}\text { At your regular clinic, you can receive routine ongoing care for a chronic problem, for example, for high } \\
\text { blood pressure (hypertension), diabetes or back pain, etc. }\end{array}$} \\
\hline \multicolumn{3}{|l|}{ Comprehensiveness } \\
\hline \multicolumn{3}{|l|}{$\begin{array}{l}\text { At your regular clinic, the doctor takes the time to talk to you about prevention and asks you about your } \\
\text { lifestyle habits }\end{array}$} \\
\hline \multicolumn{3}{|l|}{ At your regular clinic, the doctors/staff help you get all the health care services you need } \\
\hline \multicolumn{3}{|l|}{ At your regular clinic, your opinion and your preferences are taken into account in the care that you receive } \\
\hline \multicolumn{3}{|l|}{$\begin{array}{l}\text { At your regular clinic, you are helped to weigh the pros and cons when you have to make decisions about } \\
\text { your health }\end{array}$} \\
\hline \multicolumn{3}{|l|}{ At your regular clinic, your questions are clearly answered by all the clinic staff } \\
\hline \multicolumn{3}{|l|}{ At your regular clinic, the doctors spend enough time with you } \\
\hline \multicolumn{3}{|l|}{ Responsiveness } \\
\hline \multicolumn{3}{|l|}{ You feel respected when you go to your regular clinic } \\
\hline \multicolumn{3}{|l|}{ You are greeted courteously at the reception of your regular clinic } \\
\hline \multicolumn{3}{|l|}{ Your physical privacy is respected at your regular clinic } \\
\hline \multicolumn{3}{|l|}{ The premises of your regular clinic are pleasant } \\
\hline Outcomes of care & 5 & 0.849 \\
\hline \multicolumn{3}{|l|}{ The services you get at your regular clinic help you better understand your health problems } \\
\hline \multicolumn{3}{|l|}{ The services you get at your regular clinic help you prevent certain health problems before they appear } \\
\hline \multicolumn{3}{|l|}{ The services you get at your regular clinic help you control your health problems } \\
\hline \multicolumn{3}{|l|}{ The professionals you see at your regular clinic encourage you to follow the treatments prescribed } \\
\hline $\begin{array}{l}\text { The professionals you see at your regular clinic help motivate you to adopt good lifestyle habits like quitting } \\
\text { smoking, eating more healthy foods, etc. }\end{array}$ & & \\
\hline
\end{tabular}

selected adults (aged 18 years or older) in two regions of Quebec, in 2005. To ensure that the 23 territories of the Health and Social Service Centres were locally represented, the sample was non-proportionally stratified. Accordingly, all analyses were done on weighted data to account for this characteristic of the sampling frame. The survey assessed respondents' current affiliation with PHC organizations, their health services utilization level, the attributes of their experience of care, and their perception of unmet care needs. ${ }^{22,23}$

The second survey was a mail survey with response from $473 \mathrm{PHC}$ organizations in the same two regions of Quebec. This survey assessed aspects related to vision, structure, resources and practices of the PHC organizations. In each organization, a key informant, generally a doctor designated by his or her colleagues, responded to the questionnaire.
A nominal link between the two surveys was established by asking population survey respondents to identify their usual source of PHC. Response rates were $64 \%$ for the population survey and $75 \%$ for the organizational survey; $89 \%$ of respondents were linked to one of the 473 PHC organizations. For this study, we used responses from the 6222 respondents who used services in the two years prior to the study (20032005) and who could be linked to one of 
the 473 PHC organizations as their usual source of care. Further information about the surveys is available elsewhere..$^{22-24}$

\section{Variables}

Two complex constructs were operationalized in this study: experience of care and organizational model. Using a factor analysis of 23 items from the population survey, we constructed three indices of experience of care: first-contact accessibility, process of care and perceived outcomes of care. In this study, first-contact accessibility corresponds to the ease with which individuals can access and use health services, and process of care corresponds to affiliation and follow-up continuity, namely, comprehensiveness and responsiveness. Affiliation and follow-up continuity refer to conditions associated with having a regular source of care and its capacity to manage chronic diseases; comprehensiveness measures the organization's ability to respond to a wide spectrum of needs expressed by the patient; responsiveness focuses on the respect and attention given to the dignity of the person and to the non-technical aspect of care. Table 1 shows the Cronbach reliability coefficients for the three indices of experience of care and the items making up these indices.

We operationalized the indices based on an approach that measures performance by recategorizing each multiple category item into dichotomous low/high variables..$^{25,26}$ Responses in the low category received a score of zero and those in the high category a score of one. For each index, we averaged the dichotomized scores and placed each on a scale of 0 to 10 . For the purpose of the analyses, we created three dichotomous variables with each index using a cut-off point of 7.5, based on its distribution and the judgment of a panel of three experts that a score of 7.5 or higher represented better performance, whereas a score below 7.5 represented lower, but not necessarily poor, performance. As such, we analyzed three dichotomous variables of first-contact accessibility (high vs. low), process of care (high vs. low), and perceived outcomes of care (high vs. low).
We conceptualized organizations as having four dimensions: vision, resources, structure and practices. ${ }^{27}$ Vision refers to the representation, values and orientation shared by members of the organization. Resources are expressed in terms of the number of professionals and the quantity and type of technical platforms and communications technologies available. Structure consists of rules, regulations and governance that give coherence to the functioning of organizations and to relationships with their environment. Finally, practices represent clinical and organizational mechanisms supporting delivery of services. ${ }^{27}$ In total, we allocated 43 variables (described in detail elsewhere ${ }^{23}$ ) to these dimensions. Based on these 43 variables, we performed a cluster analysis of the 473 PHC organizations, and derived a taxonomy of five different models: one community model and four professional models, namely, single-provider, contact, coordination and coordination-integrated models. (These models are described in greater detail elsewhere. ${ }^{23}$ )

Table 2 presents distinctive characteristics of the models' four dimensions. As we move from left to right in Table 2, the models clearly become increasingly complex in terms of their characteristics, the most complex ones being the professional coordination-integrated model and the community models. Figure 1 shows the correspondence between currently existing types of PHC organizations in the two regions and the five models of the taxonomy.

\section{Selection of diseases}

As mentioned earlier, we used the responses from those respondents who had used services in the two years prior to the study (2003-2005) and who could be linked to one of the 473 PHC organizations as their usual source of care $(\mathrm{N}=6222)$. We asked them about their experience of care and whether a doctor had ever told them they had one or more of the chronic diseases listed in the questionnaire.* Respondents were then classified according to whether or not they had a chronic disease. Individuals with only one morbidity were classified in the corresponding morbidity category. Those with more than one morbidity were assigned to the first category of morbidity listed in decreasing order, as shown in the flow diagram (Figure 2). To ensure that the no-chronic-disease group (37.6\%) did not include any chronic disease patients, people with chronic diseases other than those being studied (15.2\%) were excluded from the analyses. Cardiovascular risk factors include diabetes, hypertension and hypercholesterolemia; for other chronic diseases, it was generally not possible to make finer distinctions within categories.

To assess the association of different organizational models with the care experience of chronic illness patients, we performed stratified logistic regressions of the three dichotomous variables of interest (access, process, outcomes) for each chronic illness group. All analyses included age, sex, income and educational level as covariates.

\section{Results}

\section{Individual characteristics and affiliation of respondents}

Table 3 shows the characteristics of respondents, including their affiliation with a community or professional model of care. Each disease group, including the group with no chronic disease, is compared to the reference group "all users." Compared with those in the "all users" reference group, individuals in the no-chronic-disease group tend to be younger, in better health, male and better educated. On the other hand, the cardiovascular-risk-factors group is older, includes more men and has a lower level of education than the reference group. The arthritic, respiratory ( $\geq 45$ years) and cardiac-disease groups share similar characteristics: individuals are older, in poorer health, and have lower education and income levels than the "all users" reference group. The arthritic and the respiratory-disease groups also include a higher percentage of women. Individuals in the respiratory disease group $(\leq 44$ years) are younger and tend to have higher levels of education and income.

\footnotetext{
* Cardiac (heart disease or heart failure), respiratory (chronic obstructive pulmonary disease [COPD], asthma), arthritic (arthritis, osteoarthritis, rheumatism), cardiovascular risk factor (hypertension, diabetes, hypercholesterolemia) or other (peripheral vascular disease, cancer).
} 
TABLE 2

Primary health care (PHC) organizations $(\mathrm{N}=473)$ surveyed, Quebec, 2003-2005

\begin{tabular}{|c|c|c|c|c|c|}
\hline \multirow[b]{2}{*}{ Characteristics } & \multicolumn{5}{|c|}{ Professional models of care } \\
\hline & Single provider & Contact & Coordination & $\begin{array}{l}\text { Coordination- } \\
\text { integrated }\end{array}$ & Community model \\
\hline \multicolumn{6}{|l|}{ Vision (values) } \\
\hline Responsibility & Clientele $^{* *}$ & Individuals who present ${ }^{* * *}$ & Clientele $^{* * *}$ & Population ${ }^{* *}$ & Population ${ }^{* * *}$ \\
\hline Continuity - accessibility & NS & Accessibility > continuity ${ }^{* * *}$ & Continuity $>$ accessibility* & NS & Continuity $>$ accessibility ${ }^{* *}$ \\
\hline Team work & Not important ${ }^{* * *}$ & NS & Important ${ }^{* * *}$ & Important ${ }^{* * *}$ & Important ${ }^{* * *}$ \\
\hline \multicolumn{6}{|l|}{ Resources } \\
\hline MDs supply & Low ${ }^{* * *}$ & Average * & $\operatorname{Low}^{* * *}$ & High ${ }^{* * *}$ & High ${ }^{* * *}$ \\
\hline Professionals supply & Low ${ }^{* * *}$ & High *** & High *** & High *** & Average ${ }^{* * *}$ \\
\hline Technical platform & Very low ${ }^{* * *}$ & NS & Average ** & High $^{* * *}$ & Average $^{* * *}$ \\
\hline $\begin{array}{l}\text { Information and commu- } \\
\text { nication technologies }\end{array}$ & Very low ${ }^{* * *}$ & NS & NS & High $^{* * *}$ & High $^{* * *}$ \\
\hline \multicolumn{6}{|l|}{ Structure } \\
\hline Governance & Prof. private ${ }^{* * *}$ & Prof. private ${ }^{* * *}$ & Prof. private ${ }^{* * *}$ & Prof. private ${ }^{* * *}$ & Public ${ }^{* * *}$ \\
\hline MD payment & FFS *** & FFS *** & FFS *** & FFS $* * *$ & Time based ${ }^{* * *}$ \\
\hline Internal collaboration & None ${ }^{* * *}$ & Informal ${ }^{* *}$ & Informal ${ }^{* * *}$ & Formal ${ }^{* * *}$ & Formal $^{* * *}$ \\
\hline Link with primary care & NS & No ${ }^{* *}$ & No ${ }^{*}$ & Yes $^{* * *}$ & NS \\
\hline $\begin{array}{l}\text { Link with specialized } \\
\text { services }\end{array}$ & NS & No ${ }^{*}$ & $\mathrm{No}^{* *}$ & Yes $^{* * *}$ & NS \\
\hline \multicolumn{6}{|l|}{ Practices } \\
\hline Appointment/walk-in & $\begin{array}{l}\text { Mostly scheduled } \\
\text { appointment*** }^{*}\end{array}$ & Mostly walk-in *** & NS & NS & NS \\
\hline Scope of services & Narrow ${ }^{* * *}$ & Narrow ${ }^{* *}$ & Broad ${ }^{* * *}$ & Very broad ${ }^{* * *}$ & Very broad ${ }^{* * *}$ \\
\hline Quality assessment & None ${ }^{* * *}$ & More or less ${ }^{* * *}$ & More or less ${ }^{* * *}$ & More ${ }^{* * *}$ & More ${ }^{* * *}$ \\
\hline
\end{tabular}

Abbreviations: FFS, fee-for-service; $\mathrm{N}$, overall sample size; $N S$, not significant; $p$, statistical significance; prof., professional

Difference between levels of the characteristics within each model

${ }^{*} p \leq .05$

${ }^{* *} p \leq .01$

*** $p \leq .001$

FIGURE 1

Correspondance between currently existing types of PHC organizations and models of the taxonomy ${ }^{\mathrm{a}}$

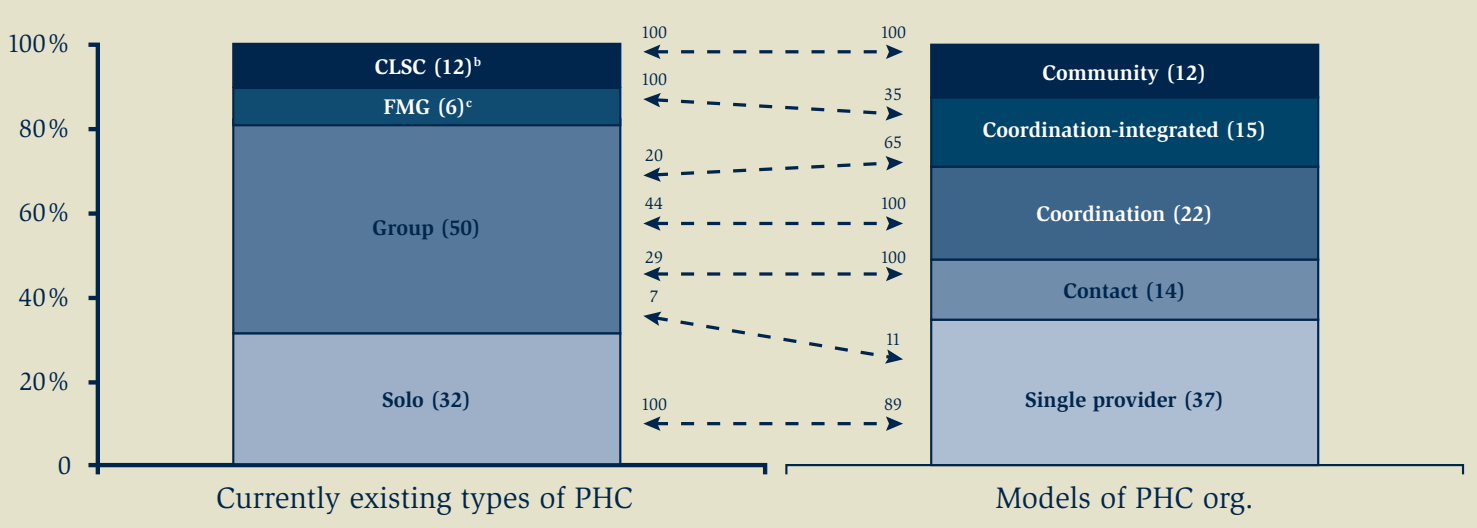

${ }^{\text {a }}$ Percentages read as follows: all (100\%) of CLSC (left bar) fall into the community category (right bar) and constitute $100 \%$ of this category

${ }^{\mathrm{b}}$ CLSC: Centres locaux de services communautaires (Local community health centers)

' FMG: Family medicine groups 
FIGURE 2

Flow diagram for assignment of survey respondents to chronic disease group

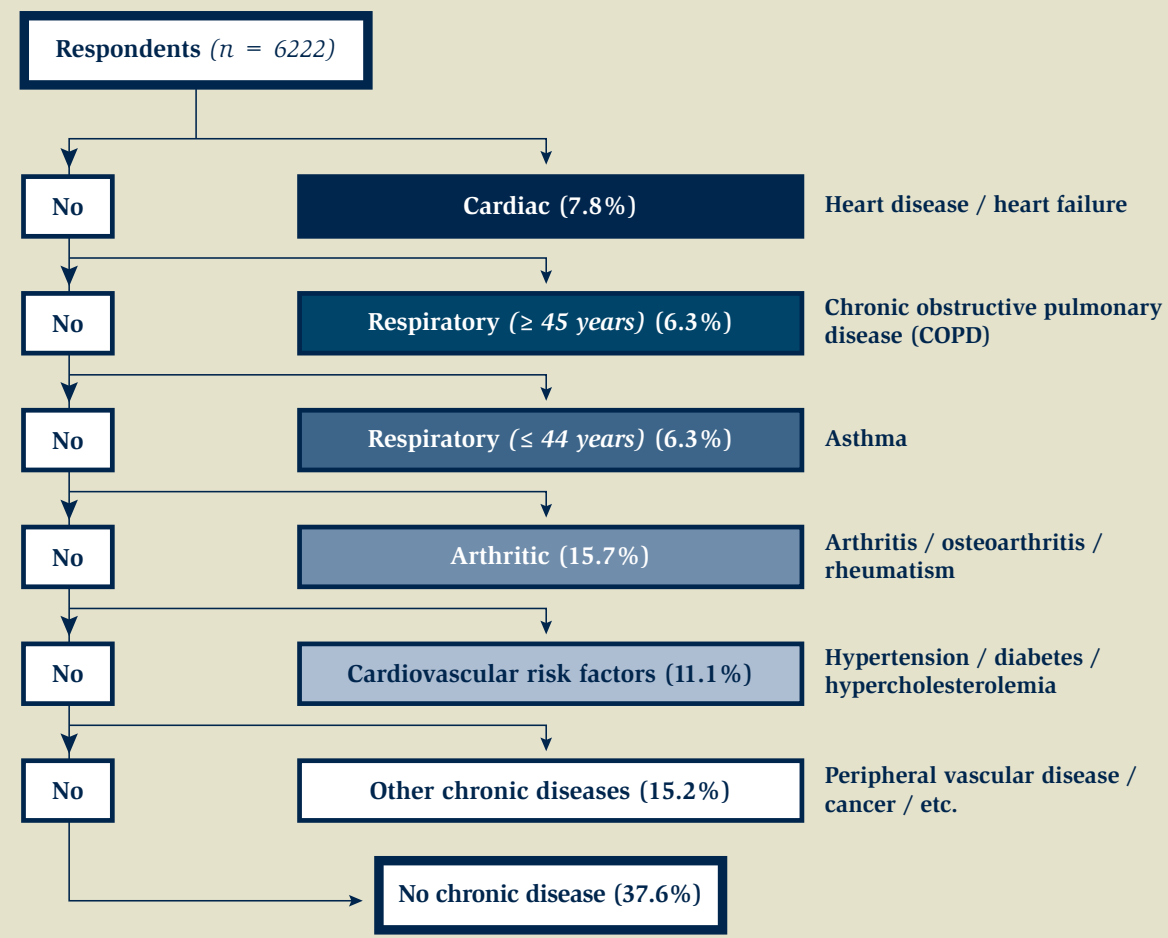

There is little variation across disease groups with respect to affiliation to the various PHC organizational models (Table 3 ). An exception, however, is the no-chronicdisease group of respondents, who tend to concentrate more in the contact model and less in the single-provider model, compared with all service users. The singleprovider model also attracts more than its share of individuals with cardiac diseases and less than its share of respiratory-disease patients ( $\leq 44$ years). Aside from these differences, the percentage of individuals affiliated with organizational models in the different chronic-disease groups is similar to the figures for all users. However, the percentage of users of services that identify each model as their regular source of care varies considerably, from $10.4 \%$ for the community model to $29.0 \%$ for the coordination-integrated model.

As we move from the no-chronic-disease to the cardiac-disease group (Table 3), perceived health status tends to deteriorate, presumably reflecting an increasing gradient of disease severity.
Further analysis of the comorbidities associated with these chronic diseases confirms this increasing degree of severity, as the number of comorbidities associated with the main morbidity increases steadily from the no-chronic-disease to the cardiacdisease group (Table 4).

\section{Experience of care by disease}

Experience of care varies across disease conditions (Table 5). First-contact accessibility presents the lowest percentage of individuals with scores of 7.5 and more, and the least variation across diseases. First-contact accessibility is slightly lower for people in the no-chronic-disease group, although there is no statistically significant difference between each chronic disease category and the all-users one.

Process of care reveals a higher percentage of individuals with scores of 7.5 and more, and with greater variation across diseases than first-contact accessibility. The respiratory group aged 44 years and less has the lowest percentage of individuals with scores of 7.5 and more, even lower than the no-chronic-disease group, whereas the cardiovascular-risk-factors group has the highest percentage. Outcomes of care follow the same pattern as process of care: the percentage of those with scores of 7.5 and more varies and is much lower for people aged 44 years and less with respiratory diseases, and higher for those with cardiovascular risk factors.

\section{Experience of care related to organizational models in different disease situations}

Table 6 shows odds ratios (ORs) with $95 \%$ confidence intervals (CIs) for relationships between the organizational models and experience of care in the different chronic disease groups, with the professional contact model as reference. Data are adjusted for respondents' characteristics except for perceived health status, which was highly correlated with the chronic diseases included in the analyses.

First-contact accessibility is better in the contact and coordination-integrated models (OR > 1 with lower limit of $\mathrm{CI} \geq 1$ ) and much worse in the single-provider model 
TABLE 3

Characteristics of population survey respondents $(\mathrm{N}=6222)$ by chronic disease group, Quebec, 2003-2005

\begin{tabular}{|c|c|c|c|c|c|c|c|}
\hline \multirow[b]{2}{*}{ Respondent characteristic } & \multicolumn{7}{|c|}{ Chronic disease group, \% } \\
\hline & All users & $\begin{array}{l}\text { No chronic } \\
\text { disease }\end{array}$ & $\begin{array}{l}\text { Cardiovascular } \\
\text { risk factors }\end{array}$ & Arthritic & $\begin{array}{l}\text { Respiratory } \\
(\leq 44 \text { years })^{\mathrm{a}}\end{array}$ & $\begin{array}{l}\text { Respiratory } \\
(\geq 45 \text { years })^{b}\end{array}$ & Cardiac \\
\hline \multicolumn{8}{|l|}{ Age } \\
\hline $18-39$ & 35.3 & $53.8^{*}$ & $8.7^{*}$ & $8.3^{*}$ & 81.5 & - & $10.1^{*}$ \\
\hline $40-54$ & 31.0 & $34.8^{*}$ & 29.4 & 27.6 & 18.5 & 41.8 & $16.5^{*}$ \\
\hline \multicolumn{8}{|l|}{ Sex } \\
\hline Male & 44.3 & $48.7^{*}$ & $56.9^{*}$ & $31.6^{*}$ & $37.7^{*}$ & $37.8^{*}$ & 46.8 \\
\hline Female & 55.7 & $51.3^{*}$ & $43.1^{*}$ & $68.4^{*}$ & $62.3^{*}$ & $62.2^{*}$ & 53.2 \\
\hline \multicolumn{8}{|l|}{ Perceived health status } \\
\hline \multicolumn{8}{|l|}{ Level of education completed } \\
\hline Primary (less than high school) & 15.6 & $6.6^{*}$ & $20.5^{*}$ & $26.3^{*}$ & $7.7^{*}$ & $24.9^{*}$ & $34.4^{*}$ \\
\hline Secondary diploma & 32.7 & 32.4 & 35.1 & 33.1 & 32.7 & 32.7 & 31.9 \\
\hline Post-secondary diploma & 24.1 & $27.5^{*}$ & $19.3^{*}$ & $19.6^{*}$ & $32.0^{*}$ & 25.1 & $17.1^{*}$ \\
\hline University degree & 27.5 & $33.5^{*}$ & 25.1 & $21.0^{*}$ & 27.6 & $17.3^{*}$ & $16.5^{*}$ \\
\hline \multicolumn{8}{|l|}{ Income, CAD } \\
\hline Less than 15,000 & 11.9 & $9.3^{*}$ & 10.3 & $15.0^{*}$ & 13.2 & $17.0^{*}$ & $18.8^{*}$ \\
\hline $15,000-34,999$ & 31.2 & $26.3^{*}$ & 33.9 & $36.8^{*}$ & $24.0^{*}$ & 35.8 & $42.1^{*}$ \\
\hline $35,000-74,999$ & 34.5 & 37.0 & 34.4 & 30.9 & 38.2 & 31.1 & $28.3^{*}$ \\
\hline Single provider & 12.5 & $10.1^{*}$ & 14.8 & 14.7 & 10.1 & 14.8 & $17.9^{*}$ \\
\hline
\end{tabular}

Abbreviations: CAD, Canadian dollars; $\mathrm{N}$, overall sample size; $\mathrm{p}$, statistical significance.

${ }^{a}$ The main morbidity in this age group ( $\leq 44$ years) is likely asthma.

${ }^{\mathrm{b}}$ The main morbidity in this age group ( $\geq 45$ years) is likely chronic obstructive pulmonary disease (COPD).

${ }^{*} \mathrm{p} \leq .05$; reference is all users

(OR $<1$ with upper limit of $\mathrm{CI}<1$ ), for all the chronic disease and no-chronic-disease groups. The community model is also among the more accessible models for arthritic as well as respiratory diseases for both age groups.

The odds ratios for process of care also vary by organizational model across diseases. The contact model tends to offer a less favourable process of care than the other models in all disease groups, as well as the no-chronic-disease group, except in the cardiovascular-risk-factors and respiratory-diseases
( $\leq 44$ years) groups. For both these groups, all organizational models other than single provider show a less favourable experience of care.

Results for outcomes of care follow the same pattern as for process of care. Those for the no-chronic-disease group follow the pattern observed for process of care more closely. The other results are similar to those for process of care, but for the most part they fail to reach statistical significance.

\section{Discussion}

Our study sheds light on the range of care experience across chronic disease conditions. It also explores the extent to which the relationship between organizational PHC models and care experience varies across different types of chronic diseases.

Two major findings emerge from our study. First, accessibility of care is relatively low for all chronic conditions, as well as for those with no chronic disease, and shows little variation across diseases. Process 
of care and outcomes of care indices are much higher for all conditions and these vary across diseases, with the highest being for the cardiovascular-risk-factors group and the lowest for respiratory-diseases $(\leq 44$ years) group.

Second, first-contact accessibility for all chronic disease conditions is more likely to be attained in the contact and the coordination-integrated models than in the other models. Conversely, first-contact accessibility is likely to be lower for patients whose regular source of care is either the single-provider or the coordination model of PHC organization.

In contrast, for process of care and, to a lesser extent, outcomes of care, the single-provider model is associated with better results than the contact model for all chronic diseases and no chronic diseases. Patients with cardiovascular risk factors and respiratory diseases ( $\leq 44$ years) report a worse process of care for all models other than the singleprovider model, while for the no-chronicdisease, arthritic, respiratory ( $\geq 45$ years) and cardiac-disease groups, all models surpass the contact model for process of care. The community model is superior for older patients ( $\geq 45$ years) with respiratory diseases, as is the coordination model for those with cardiac diseases (Table 6).

These findings on accessibility deserve a lengthier explanation. First, in our study the percentage of individuals with high score ( $\geq 7.5$ out of 10 ) of first-contact accessibility of PHC is rather low (range: $28.4 \%-32.1 \%$ ), regardless of their condition, and the percentage is much lower than for other aspects of care experience (Table 5). Other studies have also alerted us to major problems of accessibility in the delivery of PHC services. ${ }^{28-30}$ Although the variation between models is small, logistic regression analysis reveals two interesting contrasting results: the single-provider model is the least accessible at first contact, whereas the contact model is the most accessible in all conditions. Since a higher proportion of patients affiliated with the single-provider model than with the contact model have regular doctors ( $94 \%$ vs. $64 \%$ ), this suggests that having a regular doctor is not among the most important factors fostering accessibility (Figure 3). ${ }^{29,31-33}$ At least for this dimension of care experience, having a regular doctor does not seem to be the sole important factor explaining the relationship between first-contact accessibility and PHC organizational models; some intrinsic attributes of these various models, such as group practice, also seem to be important. This is due to the fact that access to health care is conceptualized in this study as having access to a specific general practitioner as well as to other doctors in the absence of one's family doctor. Obviously, solo providers fail to address this broader view of first-contact access. Conversely, the contact model possesses intrinsic features that foster first-contact accessibility (Table 2).

In comparison with first-contact accessibility, process of care and, to a lesser extent, outcomes of care show much higher percentages of individuals having high scores for all diseases. There is also greater variation across diseases, with the respiratory-diseases ( $\leq 44$ years) group having the lowest percentage and cardiovascular-risk-factors group the highest (Table 5). These differences may reflect the fact that patients in the respiratory-diseases ( $\leq 44$ years) group are less likely to have a regular doctor (63\%) than patients in the cardiovascular-risk-factors group (93\%) (Figure 4). Patients in the respiratory-diseases ( $\leq 44$ years) group are also younger than those in the cardiovascular-risk-factor groups (Table 3). Studies reveal that older patients and those who have a regular doctor are more likely to report a favourable experience of care..$^{29,31,32}$ In comparison to accessibility, process of care is much higher for patients in all the disease groups who are with the single-provider model of PHC (Table 6).

The two coordination models and the community model also generate better processes and outcomes of care than the contact model for no-chronic disease or arthritic and respiratory ( $\geq 45$ years) diseases (Table 6). This indicates that, at least for these three conditions, organizational models influence these aspects of experience of care, although part of this influence can be mediated through age of patients and their having a regular doctor. This explanation does not hold, however, for the younger no-chronic-disease group, in which a lower percentage of individuals have a regular doctor. Finally, these two factors-age and having a regular doctor-probably explain the lack of relationship, in the younger group of patients with respiratory diseases, between models and care experience, except for the single-provider model. These findings suggest a possible interaction between age and having a regular doctor that we did not explore further. The divergent pattern observed for the cardiovascularrisk-factors group is difficult to explain. Indeed, one would expect age and having a regular doctor to contribute to a better experience of care as compared to the contact model. The lack of difference among models probably reflects the fact that patients with cardiovascular risk factors are less sensitive to differential characteristics of PHC models and find their needs evenly met by the various organizational models. It is also plausible that these patients have fewer symptomatic conditions and thus require less diligent medical attention. This hypothesis remains to be tested in further analyses.

Overall, the professional coordination-integrated and the community models emerge as the ones more likely to cover the whole spectrum of care experience, in terms of accessibility, process of care and outcomes of care for most conditions. Notably, these two models yield more favourable processes of care for more severe conditions, such as cardiac, respiratory ( $\geq 45$ years) and arthritic diseases. As noted earlier, these more severe diseases also include a greater number of comorbidities and thus require a more comprehensive and integrated approach to fulfill the diversity of needs. Hence, the coordination-integrated and the community models are particularly well suited to face the growing challenge of chronic disease management.

Although the results for process of care and outcomes of care follow similar patterns, most results for outcomes of care fail to reach statistical significance. This could be due to a lack of statistical power but also to the lack of specificity of our outcomes indicators, which are largely related to prevention. The tenuous relationship between process and outcomes of care is a common 
TABLE 4

Population survey respondents $(\mathrm{N}=6222)$ with comorbidities associated with their chronic disease group

\begin{tabular}{|c|c|c|c|c|c|}
\hline \multirow[b]{2}{*}{ Chronic disease groups } & \multicolumn{5}{|c|}{ Comorbidities, \% } \\
\hline & $\begin{array}{l}\text { Cardiac } \\
\text { problems }\end{array}$ & $\begin{array}{c}\text { Respiratory } \\
\text { problems }\end{array}$ & $\begin{array}{l}\text { Arthritic } \\
\text { problems }\end{array}$ & $\begin{array}{c}\text { Cardiovascular } \\
\text { risk factors }\end{array}$ & $\begin{array}{c}\text { Other health } \\
\text { problems }\end{array}$ \\
\hline Cardiac & 100.0 & 24.3 & 45.9 & 65.4 & 74.9 \\
\hline Respiratory ( $\geq 45$ years) ${ }^{\mathrm{a}}$ & - & 100.0 & 50.0 & 38.9 & 67.2 \\
\hline Respiratory ( $\leq 44$ years) $)^{\text {b }}$ & - & 100.0 & 9.9 & 3.6 & 38.2 \\
\hline Arthritic & - & - & 100.0 & 39.1 & 51.1 \\
\hline Cardiovascular risk factors & - & - & - & 100.0 & 39.9 \\
\hline Other health problems & - & - & - & - & 100.0 \\
\hline No chronic disease & - & - & - & - & - \\
\hline
\end{tabular}

Abbreviations: $\mathrm{N}$, overall sample size.

a The main morbidity in this age group ( $\geq 45$ years) is likely chronic obstructive pulmonary disease (COPD).

${ }^{\mathrm{b}}$ The main morbidity in this age group ( $\leq 44$ years) is likely asthma.

TABLE 5

Population survey respondents $(\mathrm{N}=6222)$ who experienced better care ${ }^{\mathrm{a}}$ by chronic disease group

\begin{tabular}{|c|c|c|c|c|c|c|c|}
\hline \multirow[b]{2}{*}{ Experience of care } & \multicolumn{7}{|c|}{ Chronic disease group, \% } \\
\hline & All users & $\begin{array}{l}\text { No chronic } \\
\text { disease }\end{array}$ & $\begin{array}{c}\text { Cardiovascular } \\
\text { risk factors }\end{array}$ & Arthritic & $\begin{array}{l}\text { Respiratory } \\
\text { ( } \leq 44 \text { years) }^{\text {b }}\end{array}$ & $\begin{array}{l}\text { Respiratory } \\
\text { ( } \geq 45 \text { years) }^{c}\end{array}$ & Cardiac \\
\hline First-contact accessibility & 29.7 & 28.4 & 31.7 & 32.1 & 29.1 & 30.7 & 30.3 \\
\hline Process of care & 61.4 & $54.7^{*}$ & $79.1^{*}$ & $69.0^{*}$ & $48.8^{*}$ & $71.5^{*}$ & $69.5^{*}$ \\
\hline Outcomes of care & 56.8 & $52.4^{*}$ & $73.4^{*}$ & $62.5^{*}$ & $42.5^{*}$ & $63.9^{*}$ & $62.9^{*}$ \\
\hline
\end{tabular}

Abbreviations: $\mathrm{N}$, sample size; $\mathrm{p}$, statistical significance.

${ }^{\text {a }}$ Having a score of 7.5 out of 10 on a scale of 0 to 10 of dichotomized scores.

${ }^{\mathrm{b}}$ The main morbidity in this age group ( $\leq 44$ years) is likely asthma.

' The main morbidity in this age group ( $\geq 45$ years) is likely chronic obstructive pulmonary disease (COPD).

${ }^{*} p \leq .05$; reference is all users

finding of studies reporting on experience of care and continuity. ${ }^{34}$

Finally, our findings must also be interpreted in light of the relative importance of the five PHC organizational models presented. As shown in Table 3, the three professional models-contact, coordination and coordination-integrated-share more than $75 \%$ of the utilization coverage, whereas the community and single-provider models represent just over $10 \%$ each. Further, the single-provider model is fading out as a model of PHC organization and the community model has not demonstrated the capacity to develop beyond its current level. Hence, major improvements to our health care system will likely come from the three most widely used professional models, either by their moving towards the best performing model, identified in our study as the coordinationintegrated model, or by establishing networks in which each model accomplishes specific and complementary functions in a coordinated and integrated way.

\section{Strengths and limitations}

Our study has some limitations. Firstly, the cross-sectional design makes it difficult to infer causal relationships between models of care and care experience reported in the last two years. In addition, a recall bias may limit the accuracy and reliability of information gathered on the experience of care.

Another limitation is self-reporting of chronic conditions. Although the wording of the question referred to validation of the diagnosis by a doctor (i.e. "Has a doctor ever told you that you have diabetes?"), the response is always limited by respondents' subjective interpretation and their capacity to report medical information accurately. Likewise, it was not possible to obtain greater diagnostic specificity. For example, we broke down the category of respiratory diseases into two age categories, assuming that people aged 44 years and younger were mainly reporting asthma, while for those aged 45 years plus the main morbidity was COPD, but we were unable to validate these assumptions.

Assigning morbidities to mutually exclusive categories adds more comorbidities to the first ones appearing in the scale. At the same time, this procedure increases the heterogeneity of these categories. But given the correlation between perceived health status and categories of chronic diseases, we considered the inclusive order of categories of morbidities as accurately representing decreasing degrees of severity. However, since it remains a measure of prevalence of a diagnosis and not a true measure of health status, our analyses cannot claim to have fully controlled for severity of disease and 


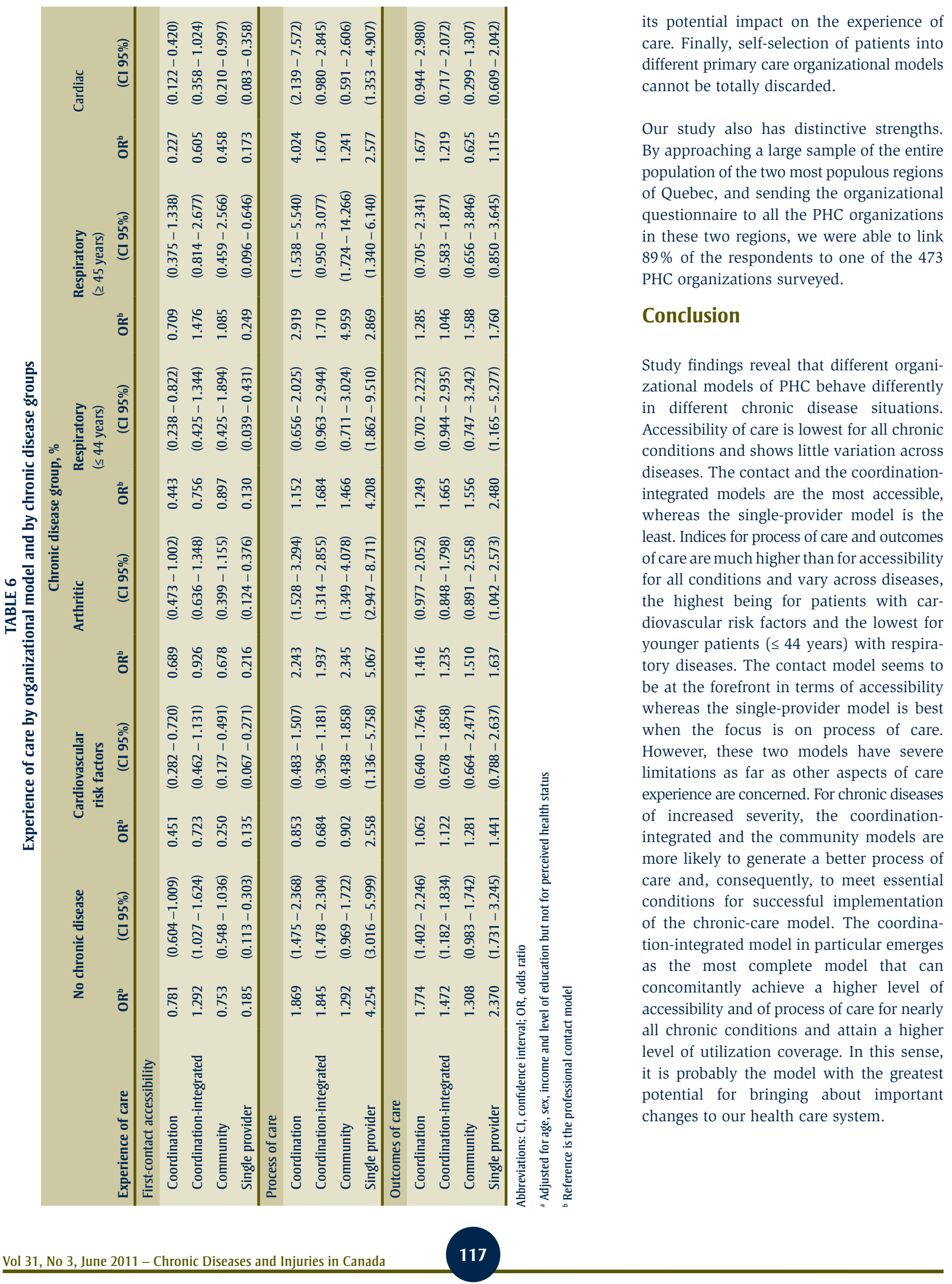


FIGURE 3

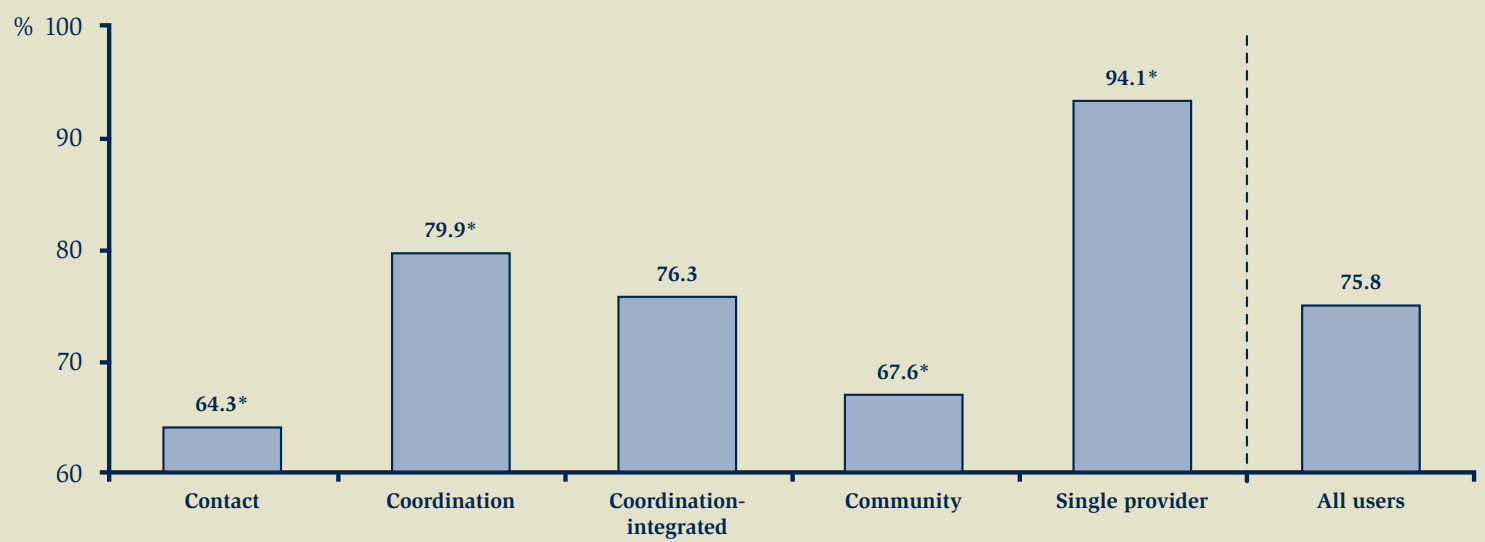

${ }^{*} p \leq .05$ Reference: All users

FIGURE 4

Percentage of survey respondents $(\mathrm{N}=6222)$ who have a regular doctor by chronic disease group

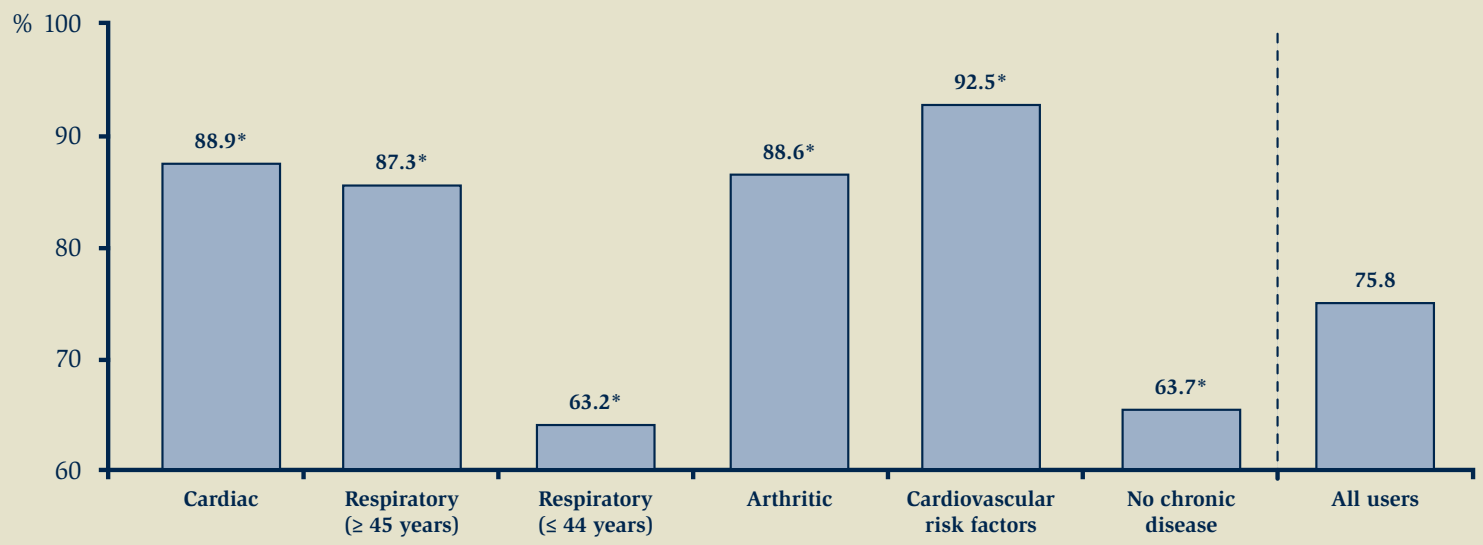

${ }^{*} p \leq .05$ Reference: All users

\section{Acknowledgements}

The data presented in this article originated from a research project funded by the Canadian Institutes of Health Research (CIHR), Canadian Health Services Research Foundation (CHSRF) and Fonds de la recherche en santé du Québec (FRSQ). Financial support was also provided by the Agence de la santé et des services sociaux de Montréal and Agence de la santé et des services sociaux de la Montérégie, Institut national de santé publique du Québec (INSPQ), Groupe de recherche sur l'équité d'accès et l'organisation des services de santé de 1re ligne (GRÉAS 1), and Groupe interuniversitaire de recherche sur les urgences (GIRU).

The authors declare that there are no conflicts of interest.

The authors wish to thank Alexandre Prud'homme, Odette Lemoine and Brigitte Simard for their contribution to the data analysis; Sylvie Gauthier and Isabelle Rioux revised the text and provided editorial assistance in preparing the manuscript.

\section{References}

1. Broemeling AM, Watson DE, Prebtani F. Population patterns of chronic health conditions, co-morbidity and healthcare use in Canada: implications for policy and practice. Healthc Q. 2008;11(3):70-6.

2. Wagner EH. Meeting the needs of chronically ill people. BMJ. 2001;323(7319):945-6.

3. Epping-Jordan JE, Pruitt SD, Bengoa R, Wagner EH. Improving the quality of health care for chronic conditions. Qual Saf Health Care. 2004;13(4):299-305. 
4. Starfield B, Lemke KW, Bernhardt T, Foldes SS, Forrest CB, Weiner JP. Comorbidity: implications for the importance of primary care in 'case' management. Ann Fam Med. 2003;1(1):8-14.

5. Starfield B, Lemke KW, Herbert R, Pavlovich WD, Anderson G. Comorbidity and the use of primary care and specialist care in the elderly. Ann Fam Med. 2005;3(2):215-22.

6. Grumbach K. Chronic illness, comorbidities, and the need for medical generalism. Ann Fam Med. 2003;1(1):4-7.

7. Broemeling AM, Watson DE, Black C. Chronic conditions and co-morbidity among residents of British Columbia. Vancouver (BC): Centre for Health Services and Policy Research, University of British Columbia; 2005.

8. Rothman AA, Wagner EH. Chronic illness management: what is the role of primary care? Ann Intern Med. 2003;138(3):256-61.

9. Davis K, Schoenbaum SC, Audet AM. A 2020 vision of patient-centered primary care. J Gen Intern Med. 2005;20(10):953-7.

10. Starfield B, Shi L. The medical home, access to care, and insurance: a review of evidence. Pediatrics. 2004;113(5 Suppl):1493-8.

11. O'Connor PJ, Sperl-Hillen JM, Pronk NP, Murray T. Primary care clinic-based chronic disease care: Features of successful programs. Dis Manag Health Out. 2001;9(12):691-8.

12. Bodenheimer T, Wagner EH, Grumbach K. Improving primary care for patients with chronic illness: the chronic care model, Part 2. JAMA. 2002;288(15):1909-14.

13. Barr VJ, Robinson S, Marin-Link B, Underhill L, Dotts A, Ravensdale D, et al. The expanded Chronic Care Model: an integration of concepts and strategies from population health promotion and the Chronic Care Model. Hosp Q. 2003;7(1):73-82.

14. Rundall TG, Shortell SM, Wang MC, Casalino L, Bodenheimer T, Gillies RR, et al. As good as it gets? Chronic care management in nine leading US physician organizations. BMJ. 2002;325(7370):958-61 .
15. Levesque JF, Feldman D, Dufresne C, Bergeron P, Pinard B, Gagné V. Barrières et éléments facilitant l'implantation de modèles intégrés de prévention et de gestion des maladies chroniques. Prat Organ Soins. 2009;40(4):251-65. French.

16. Friedberg MW, Coltin KL, Safran DG, Dresser M, Zaslavsky AM, Schneider EC. Associations between structural capabilities of primary care practices and performance on selected quality measures. Ann Intern Med. 2009;151(7):456-63.

17. Shortell SM, Marsteller JA, Lin M, Pearson ML, Wu SY, Mendel P, et al. The role of perceived team effectiveness in improving chronic illness care. Med Care. 2004;42(11):1040-8.

18. Russell GM, Dahrouge S, Hogg W, Geneau R, Muldoon L, Tuna M. Managing chronic disease in Ontario primary care: the impact of organizational factors. Ann Fam Med. 2009;7(4):309-18.

19. Glazier RH, Klein-Geltink J, Kopp A, Sibley LM. Capitation and enhanced fee-forservice models for primary care reform: a population-based evaluation. CMAJ. 2009;180(11):E72-E81.

20. Tsai AC, Morton SC, Mangione CM, Keeler EB. A meta-analysis of interventions to improve care for chronic illnesses. Am J Manag Care. 2005;11(8):478-88.

21. Cretin S, Shortell SM, Keeler EB. An evaluation of collaborative interventions to improve chronic illness care: Framework and study design. Eval Rev. 2004;28(1):28-51.

22. Levesque JF, Pineault R, Simard B, Roberge D, Hamel M, Kapetanakis C, et al. L'expérience de soins de la population: portrait des variations intra-régionales à Montréal et en Montérégie [Internet]. Montréal (QU): Institut national de santé publique du Québec; 2007 [cited 2010 Nov 8]. Available from: http://www .inspq.qc.ca/pdf/publications/627-ExperienceDeSoinsDeLaPopulation.pdf French. Jointly published by Direction de santé publique de l'Agence de la santé et des services sociaux de Montréal.
23. Pineault $\mathrm{R}$, Levesque JF, Roberge $\mathrm{D}$, Hamel M, Lamarche P, Haggerty J. Accessibility and continuity of care: a study of primary healthcare in Québec. Research report presented to the Canadian Institutes of Health Research and the Canadian Health Services Research Foundation [Internet]. Montréal (QU): Direction de santé publique de l'Agence de la santé et des services sociaux de Montréal; 2009 [cited 2010 Nov 8]. Available from: http://www.inspq.qc.ca/pdf/publications /911_ServicesPremLigneANGLAIS.pdf Jointly published by Institut national de santé publique du Québec and Centre de recherche de l'Hôpital Charles LeMoyne.

24. Hamel M, Pineault R, Levesque JF, Roberge D, Lozier-Sergerie A, Prud'homme A, Simard B. L'organisation des services de santé de première ligne: portrait des services médicaux de première ligne à Montréal et en Montérégie. Montréal (QU): Institut national de santé publique du Québec; 2007 [cited 2010 Nov 8]. http://www.inspq.qc.ca/pdf/ publications/726-OrganisationServices.pdf French. Jointly published by Direction de santé publique de l'Agence de la santé et des services sociaux de Montréal.

25. Nietert PJ, Wessell AM, Jenkins RG, Feifer C, Nemeth LS, Ornstein SM. Using a summary measure for multiple quality indicators in primary care: the Summary QUality InDex (SQUID). Implement Sci. 2007;2:11.

26. Feifer C, Nemeth L, Nietert PJ, Wessell AM, Jenkins RG, Roylance L, et al. Different paths to high-quality care: three archetypes of top-performing practice sites. Ann Fam Med. 2007;5(3):233-41.

27. Lamarche PA, Beaulieu MD, Pineault R, Contandriopoulos AP, Denis JL, Haggerty J. Choices for change: the path for restructuring primary healthcare services in Canada. Ottawa (ON): Canadian Health Services Research Foundation; 2003.

28. Schoen C, Osborn R, Doty MM, Bishop M, Peugh J, Murukutla N. Toward higher-performance health systems: adults' health care experiences in seven countries, 2007. Health Aff (Millwood). 2007;26(6):w717-34. 
29. Canadian Institute for Health Information. Experiences with primary health care in Canada. Ottawa (ON): Canadian Institute for Health Information; 2009 [cited 2010 May 4]. Available from: http://secure.cihi .ca/cihiweb/products/cse_phc_aib_en.pdf

30. Sanmartin C, Ross N. Experiencing difficulties accessing first-contact health services in Canada: Canadians without regular doctors and recent immigrants have difficulties accessing first-contact healthcare services. Reports on difficulties in accessing care vary by age, sex and region. Healthc Policy. 2006;1(2):103-19.

31. Nutting PA, Goodwin MA, Flocke SA, Zyzanski SJ, Stange KC. Continuity of primary care: to whom does it matter and when? Ann Fam Med. 2003;1(3):149-55.

32. Haggerty JL, Pineault R, Beaulieu MD, Brunelle Y, Gauthier J, Goulet F, et al. Room for improvement: patients' experiences of primary care in Quebec before major reforms. Can Fam Physician. 2007;53(6):1056-7.

33. Starfield B. Primary Care: Balancing health needs, services and technology. New York: Oxford University Press; 1998.

34. Christakis DA. Continuity of care: process or outcome? Ann Fam Med. 2003;1(3):131-3. 